\title{
Ankle/brachial index to everyone
}

\author{
Giuseppe Giugliano', Anna Sannino ${ }^{1}$, Linda Brevetti ${ }^{1}$, Cinzia Perrino ${ }^{1}$, Gabriele Giacomo Schiattarella', \\ Anna Franzone ${ }^{1}$, Federica Serino ${ }^{1}$, Marco Ferrone ${ }^{1}$, Fernando Scudiero ${ }^{1}$, Andreina Carbone ${ }^{1}$, Michele De Paulis ${ }^{1}$, \\ Raffaele Izzo', Bruno Amato², Bruno Trimarco', Giovanni Esposito ${ }^{1 *}$
}

From XXV National Congress of the Italian Society of Geriatric Surgery

Padova, Italy. 10-11 May 2012

\begin{abstract}
Background: In the last years significant attention has been paid in identifying markers of subclinical atherosclerosis or of increased cardiovascular risk.

Method: An abnormal ankle/brachial index (ABI) identifies patients affected by lower extremity peripheral arterial disease, and even more important, represents a powerful predictor of the development of future ischemic cardiovascular events.
\end{abstract}

Conclusions: In our opinion, $A B \mid$ is a cardiovascular risk prediction tool with very desirable properties that might become a routine measurement in clinical practice.

Cardiovascular diseases are the leading causes of morbidity and mortality in the western world [1-4], and atherosclerosis is the underlying cause of the majority of cardiovascular diseases [5,6]. Lower extremity peripheral arterial disease (LE-PAD) is one of the main manifestations of atherosclerosis affecting about $20 \%$ of the population aged 55 and older [7,8]. It has been calculated that about 27 millions people in Europe and United States suffer from this pathology [9], thus representing a socioeconomic problem of great magnitude [10]. In particular, elderly populations have more severe forms of atherosclerosis with a higher prevalence of polidistrectual disease including carotid arteries and abdominal aorta [11-13] and develop a higher grade of disability compared with younger people [14]. In addition to be an important cause of disability in its symptomatic forms (intermittent claudication and critical limb ischemia), LE-PAD is associated with an elevated risk of developing ischemic cardiovascular events [3,6,15-17], which is similar in symptomatic and asymptomatic patients [16-20].

LE-PAD diagnosis can be made simply, accurately and non-invasively by ankle/brachial index (ABI) measurement

\footnotetext{
* Correspondence: espogiov@unina.it

'Department of Clinical Medicine and Cardiovascular and Immunological

Sciences, "Federico II" University", via Pansini 5, 80131, Naples, Italy

Full list of author information is available at the end of the article
}

$[8,18,21]$. The assessment involves placing a sphygmomanometer cuff just above the ankle and using a Doppler instrument to measure the systolic pressure of the posterior tibial and dorsalis pedis arteries of each leg. The $\mathrm{ABI}$ is then obtained dividing the systolic pressure of each of the ankles by the highest brachial pressure of either arm [21]. A patient's $A B I$ is defined as the lowest of the leg $A B I$ measurements (Figure 1). A resting ABI value $\leq 0.90$ defines the presence of LE-PAD and it has a sensibility of about $95 \%$ in identifying the presence of a hemodynamically significant arterial stenosis at angiography between heart and foot and near $100 \%$ specificity in excluding a normal subject [18]. Furthermore, ABI gives important information about LE-PAD severity, which is higher with a lower ABI value. In addition to its diagnostic utility, an abnormal ABI value represents a powerful predictor of the development of future ischemic cardiovascular events $[3,18,21,22]$. Such risk increases with the decrement of the $A B I$ value and it is independent of the presence or absence of the classic cardiovascular risk factors [22]. In this regard, it is important to note that although classic cardiovascular risk factors are useful to predict risk in populations, their accuracy in predicting cardiovascular risk in individuals varies considerably. Indeed, in the last years significant attention has been paid in identifying markers of subclinical atherosclerosis or of increased cardiovascular 


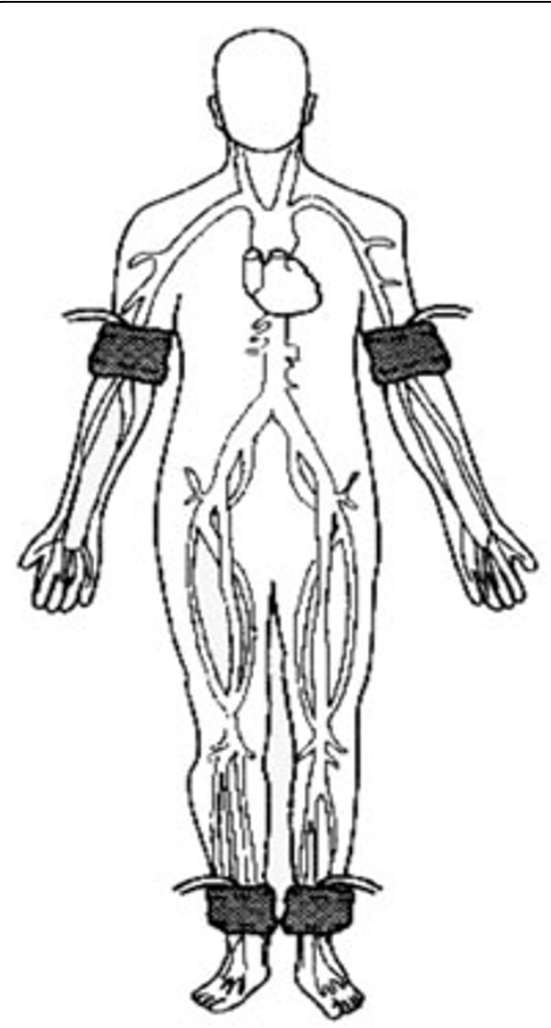

\section{Right ABI:}

\section{Higher of the right ankle systolic pressures (posterior tibial or dorsalis pedis)}

Higher arm systolic pressures (left or right arm)

\section{Left ABI:}

\section{Higher of the left ankle systolic pressures (posterior tibial or dorsalis pedis)}

Higher arm systolic pressures (left or right arm)

Figure 1 How to perform ankle/brachial index.

risk in humans as well as animal models [23-27]. Although several tools have been proposed [27-29], frequently the clinical utility of measuring such markers remains uncertain for several reasons, including costs, low reproducibility, conflicting studies or lack of confirmatory studies, and lack of measurement standardization [27]. Additional research will be needed to quantify the impact and cost effectiveness of these markers on patient management and clinical outcomes, with simplicity of assessment and low cost being the essential characteristics of an optimal risk marker.

Given that the vast majority of LE-PAD patients is asymptomatic and that an abnormal ABI has an important power in predicting the occurrence of future cardiac and cerebrovascular ischemic events, it would be extremely important to identify which populations need to be screened with this inexpensive tool. Several epidemiologic studies, including the PARTNERS [8], and the latest guidelines $[18,21]$ suggest that subjects who should undergo to $\mathrm{ABI}$ measurement are:

- All subjects who have exertion leg symptoms (also atypical) or not healing wounds;

- All subjects of 50 years and older with a history of smoking or diabetes;

- All subjects with age $>65$ years independent from the presence of cardiovascular risk factors.
Although such recommendations are already quite extensive, in our opinion they could be even broadened, given the non-invasive nature, the low cost and the elevated sensibility and specificity of ABI. In particular, all patients with coronary artery disease (CAD) should be screened, since in this population the presence of LE-PAD is relatively frequent (16-20\%), entails a higher severity of the coronary disease [30,31], and is associated with a worse prognosis [32]. Given the multidistrectual nature of atherosclerosis, also patients affected by cerebrovascular disease should undergo $\mathrm{ABI}$ measurement to identify, like in CAD, a subgroup at even higher risk that should receive higher clinical consideration.

Noteworthy, ABI has the power to provide additional risk stratification of those subjects who have a 10-year intermediate cardiovascular risk (between 10 and 20\%) $[21,33]$. In these individuals, the finding of an abnormal $\mathrm{ABI}$ value switches the patients towards a higher cardiovascular risk which needs secondary prevention, while a normal ABI could lower the risk estimation to the need of primary prevention. Identification of individuals with asymptomatic lower extremity PAD is of utmost importance, so that therapeutic interventions known to diminish their increased risk of myocardial infarction, stroke, and death may be offered [3]. Smoking cessation, lipid lowering, diabetes and hypertension treatment and antiplatelet 
therapy are recommended to reduce the risk of adverse cardiovascular ischemic events [34]. In this context, it should be acknowledged that statins are particularly effective in reducing cardiovascular risk of patients with LE-PAD, even if with normal cholesterol levels [35]. In conclusion, because of the simplicity of execution and for the diagnostic and prognostic importance, ABI, in our opinion, might become a routine measurement in clinical practice, also in the general practitioner setting. Indeed, early identification of subclinical atherosclerosis and LE-PAD might offer a unique opportunity to put on time into effect the necessary prevention measures.

\section{List of abbreviations}

LE-PAD: Lower Extremity Peripheral Arterial Disease; ABI: Ankle/Brachial Index; PARTNERS: PAD Awareness, Risk, and Treatment New Resources for Survival; CAD: Coronary Artery Disease.

\section{Acknowledgements}

This article has been published as part of BMC Surgery Volume 12 Supplement 1, 2012: Selected articles from the XXV National Congress of the Italian Society of Geriatric Surgery. The full contents of the supplement are available online at http://www.biomedcentral.com/bmcsurg/supplements/12/S1.

\section{Author details}

'Department of Clinical Medicine and Cardiovascular and Immunological Sciences, "Federico II" University", via Pansini 5, 80131, Naples, Italy. ${ }^{2}$ Department of General, Geriatric, Oncologic Surgery and Advanced Technologies, "Federico II" University", via Pansini 5, 80131, Naples, Italy.

\section{Authors' contributions}

GG: conception and design, interpetration of data, given final approval of the version to be published; $A S, L B, C P, G G S, A F, F S, M F, F S, A C, M D P$ : acquisition of data, drafting the manuscript, given final approval of the version to be published; RI, BA, BT: critical revision, interpretation of data, given final approval of the version to be published; GE: conception and design, critical revision, given final approval of the version to be published.

\section{Competing interests}

The authors declare that they have no competing interests.

Published: 15 November 2012

\section{References}

1. Morrow DA, Braunwald E, Bonaca MP, Ameriso SF, Dalby AJ, Fish MP, Fox KA, Lipka LI, Liu X, Nicolau JC, et al: Vorapaxar in the secondary prevention of atherothrombotic events. The New England journal of medicine 2012, 366:1404-1413.

2. Cassese S, Esposito G, Mauro C, Varbella F, Carraturo A, Montinaro A, Cirillo P, Galasso G, Rapacciuolo A, Piscione F: MGUard versus bAre-metal stents plus manual thRombectomy in ST-elevation myocarDial infarction pAtieNts-(GUARDIAN) trial: study design and rationale. Catheterization and cardiovascular interventions: official journal of the Society for Cardiac Angiography \& Interventions 2012, 79:1118-1126.

3. Giugliano G, Di Serafino L, Perrino C, Schiano V, Laurenzano E, Cassese S, De Laurentis M, Schiattarella GG, Brevetti L, Sannino A, et al: Effects of successful percutaneous lower extremity revascularization on cardiovascular outcome in patients with peripheral arterial disease. International journal of cardiology 2012.

4. Mannacio V, Di Tommaso L, De Amicis V, Lucchetti V, Pepino P, Musumeci F, Vosa C: Previous percutaneous coronary interventions increase mortality and morbidity after coronary surgery. The Annals of thoracic surgery 2012, 93:1956-1962.

5. Contaldi C, Losi MA, Rapacciuolo A, Prastaro M, Lombardi R, Parisi V, Parrella LS, Di Nardo C, Giamundo A, Puglia R, et al: Percutaneous treatment of patients with heart diseases: selection, guidance and follow-up. A review. Cardiovascular ultrasound 2012, 10:16.

6. Schiano V, Sirico G, Giugliano G, Laurenzano E, Brevetti L, Perrino C, Brevetti G, Esposito G: Femoral plaque echogenicity and cardiovascular risk in claudicants. JACC Cardiovascular imaging 2012, 5:348-357.

7. Meijer WT, Hoes AW, Rutgers D, Bots ML, Hofman A, Grobbee DE: Peripheral arterial disease in the elderly: The Rotterdam Study. Arteriosclerosis, thrombosis, and vascular biology 1998, 18:185-192.

8. Hirsch AT, Criqui MH, Treat-Jacobson D, Regensteiner JG, Creager MA, Olin JW, Krook SH, Hunninghake DB, Comerota AJ, Walsh ME, et al: Peripheral arterial disease detection, awareness, and treatment in primary care. JAMA : the journal of the American Medical Association 2001, 286:1317-1324.

9. Weitz Jl, Byrne J, Clagett GP, Farkouh ME, Porter JM, Sackett DL, Strandness DE Jr., Taylor LM: Diagnosis and treatment of chronic arterial insufficiency of the lower extremities: a critical review. Circulation 1996, 94:3026-3049.

10. Brevetti G, Chiariello M: Peripheral arterial disease: the magnitude of the problem and its socioeconomic impact. Current drug targets Cardiovascular \& haematological disorders 2004, 4:199-208

11. Romano M, Mainenti PP, Imbriaco M, Amato B, Markabaoui K, Tamburrini O, Salvatore M: Multidetector row $\mathrm{CT}$ angiography of the abdominal aorta and lower extremities in patients with peripheral arterial occlusive disease: diagnostic accuracy and interobserver agreement. European journal of radiology 2004, 50:303-308.

12. Romano M, Amato B, Markabaoui K, Tamburrini O, Salvatore M: Follow-up of patients with previous vascular interventions: role of multidetector row computed tomographic angiography of the abdominal aorta and lower extremities. The Journal of cardiovascular surgery 2004, 45:89-91.

13. Amato B, Markabaoui AK, Piscitelli V, Mastrobuoni G, Persico F, luliano G, Masone S, Persico G: Carotid endarterectomy under local anesthesia in elderly: is it worthwhile? Acta bio-medica : Atenei Parmensis 2005, 76(Suppl 1):64-68.

14. Cacciatore F, Abete P, Maggi S, Luchetti G, Calabrese C, Viati L, Leosco D, Ferrara N, Vitale DF, Rengo F: Disability and 6-year mortality in elderly population. Role of visual impairment. Aging clinical and experimental research 2004, 16:382-388.

15. Criqui MH, Langer RD, Fronek A, Feigelson HS, Klauber MR, McCann TJ, Browner D: Mortality over a period of 10 years in patients with peripheral arterial disease. The New England journal of medicine 1992, 326:381-386.

16. Leng GC, Lee AJ, Fowkes FG, Whiteman M, Dunbar J, Housley E, Ruckley CV: Incidence, natural history and cardiovascular events in symptomatic and asymptomatic peripheral arterial disease in the general population. International journal of epidemiology 1996, 25:1172-1181.

17. Hooi JD, Kester AD, Stoffers HE, Rinkens PE, Knottnerus JA, van Ree JW: Asymptomatic peripheral arterial occlusive disease predicted cardiovascular morbidity and mortality in a 7-year follow-up study. Journal of clinical epidemiology 2004, 57:294-300.

18. Rooke TW, Hirsch AT, Misra S, Sidawy AN, Beckman JA, Findeiss LK, Golzarian J, Gornik HL, Halperin JL, Jaff MR, et al: 2011 ACCF/AHA Focused Update of the Guideline for the Management of Patients With Peripheral Artery Disease (updating the 2005 guideline): a report of the American College of Cardiology Foundation/American Heart Association Task Force on Practice Guidelines. Journal of the American College of Cardiology 2011, 58:2020-2045.

19. Perrino C, Scudiero L, Petretta MP, Schiattarella GG, De Laurentis M, llardi F, Magliulo F, Carotenuto G, Esposito G: Total occlusion of the abdominal aorta in a patient with renal failure and refractory hypertension: a case report. Monaldi archives for chest disease Archivio Monaldi per le malattie del torace / Fondazione clinica del lavoro, IRCCS [and] Istituto di clinica tisiologica e malattie apparato respiratorio, Universita di Napoli, Secondo ateneo 2011, 76:43-46.

20. Borgia F, Di Serafino L, Sannino A, Gargiulo G, Schiattarella GG, De Laurentis M, Scudiero L, Perrino C, Piscione F, Esposito G, Chiariello M: AngioJet rheolytic thrombectomy for acute superficial femoral artery stent or femoropopliteal by-pass thrombosis. Monaldi archives for chest disease $=$ Archivio Monaldi per le malattie del torace $/$ Fondazione clinica del lavoro, IRCCS [and] Istituto di clinica tisiologica e malattie apparato respiratorio, Universita di Napoli, Secondo ateneo 2010, 74:76-81. 
21. Norgren L, Hiatt WR, Dormandy JA, Nehler MR, Harris KA, Fowkes FG: InterSociety Consensus for the Management of Peripheral Arterial Disease (TASC II). J Vasc Surg 2007, 45(Suppl S):S5-67.

22. Heald CL, Fowkes FG, Murray GD, Price JF: Risk of mortality and cardiovascular disease associated with the ankle-brachial index: Systematic review. Atherosclerosis 2006, 189:61-69.

23. Esposito G, Perrino C, Schiattarella GG, Belardo L, di Pietro E, Franzone A, Capretti G, Gargiulo G, Pironti G, Cannavo A, et al: Induction of mitogenactivated protein kinases is proportional to the amount of pressure overload. Hypertension 2010, 55:137-143.

24. Perrino C, Feliciello A, Schiattarella GG, Esposito G, Guerriero R, Zaccaro L, Del Gatto A, Saviano M, Garbi C, Carangi R, et al: AKAP121 downregulation impairs protective CAMP signals, promotes mitochondrial dysfunction, and increases oxidative stress. Cardiovascular research 2010, 88:101-110.

25. Perrino C, Rockman HA, Chiariello M: Targeted inhibition of phosphoinositide 3-kinase activity as a novel strategy to normalize betaadrenergic receptor function in heart failure. Vascular pharmacology 2006, 45:77-85.

26. Esposito G, Perrino C, Cannavo A, Schiattarella GG, Borgia F, Sannino A, Pironti G, Gargiulo G, Di Serafino L, Franzone A, et al: EGFR trans-activation by urotensin II receptor is mediated by beta-arrestin recruitment and confers cardioprotection in pressure overload-induced cardiac hypertrophy. Basic research in cardiology 2011, 106:577-589.

27. Pearson TA, Mensah GA, Alexander RW, Anderson JL, Cannon RO 3rd, Criqui M, Fadl YY, Fortmann SP, Hong Y, Myers GL, et al: Markers of inflammation and cardiovascular disease: application to clinical and public health practice: A statement for healthcare professionals from the Centers for Disease Control and Prevention and the American Heart Association. Circulation 2003, 107:499-511.

28. Xu D, Zou L, Xing Y, Hou L, Wei Y, Zhang J, Qiao Y, Hu D, Xu Y, Li J, Ma Y: Diagnostic Value of Ankle-Brachial Index in Peripheral Arterial Disease: A Meta-Analysis. The Canadian journal of cardiology 2012.

29. Perrino C, Gargiulo G, Pironti G, Franzone A, Scudiero L, De Laurentis M, Magliulo F, llardi F, Carotenuto G, Schiattarella GG, Esposito G: Cardiovascular effects of treadmill exercise in physiological and pathological preclinical settings. American journal of physiology Heart and circulatory physiology 2011, 300:H1983-1989.

30. Papamichael CM, Lekakis JP, Stamatelopoulos KS, Papaioannou TG, Alevizaki MK, Cimponeriu AT, Kanakakis JE, Papapanagiotou A, Kalofoutis AT, Stamatelopoulos SF: Ankle-brachial index as a predictor of the extent of coronary atherosclerosis and cardiovascular events in patients with coronary artery disease. The American journal of cardiology 2000, 86:615-618.

31. Brevetti G, Piscione F, Silvestro A, Galasso G, Di Donato A, Oliva G, Scopacasa F, Chiariello M: Increased inflammatory status and higher prevalence of three-vessel coronary artery disease in patients with concomitant coronary and peripheral atherosclerosis. Thrombosis and haemostasis 2003, 89:1058-1063.

32. Cotter G, Cannon CP, McCabe CH, Michowitz Y, Kaluski E, Charlesworth A, Milo O, Bentley J, Blatt A, Krakover R, et al: Prior peripheral arterial disease and cerebrovascular disease are independent predictors of adverse outcome in patients with acute coronary syndromes: are we doing enough? Results from the Orbofiban in Patients with Unstable Coronary Syndromes-Thrombolysis In Myocardial Infarction (OPUS-TIMI) 16 study. American heart journal 2003, 145:622-627.

33. Norgren L, Hiatt WR, Dormandy JA, Nehler MR, Harris KA, Fowkes FG, Bell K Caporusso J, Durand-Zaleski I, Komori K, et al: Inter-Society Consensus for the Management of Peripheral Arterial Disease (TASC II). European journal of vascular and endovascular surgery: the official journal of the European Society for Vascular Surgery 2007, 33(Suppl 1):S1-75.

34. Esposito G: Responsiveness to P2Y12 receptor inhibitors. Current opinion in cardiology 2011, 26(Suppl 1):S31-37.

35. MRC/BHF Heart Protection Study of cholesterol lowering with simvastatin in 20,536 high-risk individuals: a randomised placebocontrolled trial. Lancet 2002, 360:7-22.

doi:10.1186/1471-2482-12-S1-S18

Cite this article as: Giugliano et al: Ankle/brachial index to everyone. BMC Surgery 2012 12(Suppl 1):S18.

\section{Submit your next manuscript to BioMed Central and take full advantage of:}

- Convenient online submission

- Thorough peer review

- No space constraints or color figure charges

- Immediate publication on acceptance

- Inclusion in PubMed, CAS, Scopus and Google Scholar

- Research which is freely available for redistribution

Submit your manuscript at www.biomedcentral.com/submit
C Biomed Central 